\title{
Conviviendo con la escasez. Cultura y adaptabilidad pesquera en el lago de Chapala
}

\author{
Carmen Pedroza Gutiérrez,* Jaime Chavolla**
}

Perfiles Latinoamericanos, 26(51)

2018 | pp. 89-121

DOI: $10.18504 / \mathrm{pl} 2651-004-2018$

\begin{abstract}
Resumen
Este artículo examina las respuestas adaptativas de comunidades lacustres ante cambios ambientales. En particular se estudian las localidades cercanas al lago de Chapala, el cual se encuentra en riesgo por las oscilaciones en su nivel de agua. Estos cambios implican una reorganización social, en especial para grupos como los pescadores que son directamente dependientes de la integridad lacustre. Utilizando un marco sobre adaptación y adaptabilidad, se contrastan diversas estrategias históricas y actuales para enfrentar la escasez y el estrés lacustre en La Palma, Michoacán. Con ello pretendemos resaltar el lugar social cambiante de la pesca y sus características culturales más influyentes, las cuales han permitido su continuidad.
\end{abstract}

\begin{abstract}
This paper examines different adaptive responses that lakeside communities develop when faced with environmental change. The focus lies particularly on rural towns near lake Chapala, Mexico, affected by water level fluctuations. These situations require social reorganization, especially among groups whose survival is directly dependent on the lake's integrity, such as fishermen. Using an adaptation and adaptability framework, various historical and current strategies used to confront scarcity and lake stress in La Palma, Michoacán are contrasted. Our aim is to highlight the changing social position of the fishing trade, and its most influential cultural features that have allowed its continuity.
\end{abstract}

Palabras clave: escasez lacustre, pesca, lago de Chapala, cultura rural.

Keywords: Lake stress, fishing, lake Chapala, rural culture.

* Doctora en Estudios para el Desarrollo por la École de Hautes Études en Sciences Sociales, París, Francia. Investigadora, Unidad Académica de Estudios Regionales, Universidad Nacional Autónoma de México | pedrozacarmen@yahoo.com

** Doctor en Estudios Latinoamericanos por la Universidad Nacional Autónoma de México. Coordinador de Humanidades y Artes, Escuela Nacional de Estudios Superiores Unidad Morelia, Universidad Nacional Autónoma de México | jchavolla@enesmorelia.unam.mx 


\section{Introducción ${ }^{1}$}

E

cada vez más difícil acceso a los recursos naturales, causado por cambios ambientales y actividades antropogénicas, afecta seriamente a comunidades cuya identidad y bienestar dependen del uso directo de esos recursos. Las variaciones en la disponibilidad y calidad de estos bienes repercuten en las formas de producción, en los ingresos y en las prácticas socioculturales relacionadas con su aprovechamiento cotidiano. El resultado se traduce en cambios que, para ser enfrentados, requieren del rediseño e implementación de diversas estrategias de adaptación basadas en prácticas y elementos culturales. Una de las actividades amenazadas por el deterioro y escasez de un recurso natural y vital como el agua es la pesca de aguas interiores, actividad tradicional que forma parte del sustento familiar de comunidades rurales ribereñas en lagos y ríos.

El caso de la problemática ambiental hídrica en México tiene una relación directa con los modelos de desarrollo aplicados a lo largo de la historia del país. En especial, con aquellos cuyo enfoque en el sector primario prioriza la producción ganadera y agrícola. Históricamente, estos proyectos han rediseñado cuencas hidrológicas orientando gran parte de su aprovechamiento al sector industrial y a sistemas de riego para producción agrícola (Wolfe, 2013). Ello deja de lado el manejo del agua relacionado con el impulso o mantenimiento de la producción pesquera (Paré, 1989).

Las consecuencias de tales modelos para México se vuelven más complejas cuando se trata de la pesca en aguas continentales, ya que su aprovechamiento depende de diversos usuarios cuyos objetivos e intereses productivos son diferentes (Welcomme, 2011). Esto origina una problemática multicausal, de la que los factores responsables incluyen la construcción de obras hidráulicas, el crecimiento urbano, la desecación, extracción y degradación de la calidad de las aguas por actividades agrícolas, forestales, industriales y domésticas, así como la introducción de especies dulceacuícolas exóticas (De la Vega, 2003). Y cabe agregar a agentes climáticos como El Niño, que no siempre influyen de forma favorable en la precipitación y en la evaporación del agua (Filonov, Tereshchenko \& Mozón, 1998; Tereshchenko et al., 2002).

La cuenca Lerma-Chapala es uno de los sistemas hídricos más importantes del país y se encuentra afectada por esos factores. Sus zonas de recarga están ocupadas por altas densidades poblacionales, mismas que a su vez contaminan presas y

1 Los autores agradecen los apoyos financieros de la UNAM, PAPIT IB300212, y a su Programa de Becas Posdoctorales, por los que fue posible realizar este proyecto; así como el apoyo de las cooperativas pesqueras de La Palma, de la Jefatura de Tenencia de La Palma y de la Oficina del Distrito de Riego número 6. 
lagos (Villanueva et al., 2012). El lago de Chapala forma parte de esta cuenca. Las actividades humanas y la variabilidad hidroclimática natural han afectado el nivel de captación y calidad de su agua (Stahle et al., 2011; Tereshchenko et al., 2002). Estas condiciones colocan en riesgo su integridad además de que estresan y amenazan las actividades que son importantes para la identidad cultural y el desarrollo local. Michoacán, por ejemplo, es uno de los estados del país históricamente sobresaliente en la pesca continental. Sin embargo, también es una entidad cuyas tradiciones lacustres sufren por las consecuencias del estrés hídrico y contaminación de sus cuerpos de agua continentales.

Considerando este contexto, el objetivo del presente artículo es identificar y analizar las respuestas adaptativas de las comunidades lacustres ante los cambios naturales y antropogénicos en el medio físico, así como señalar los elementos que, por una parte, han limitado el desarrollo de la pesca continental, y, por la otra, han permitido que se mantenga como una actividad importante para las comunidades ribereñas de lagos y ríos. El mayor interés aquí gira en torno a los usuarios directos, pescadores michoacanos particularmente, afectados por reubicaciones de la ribera del lago de Chapala, considerando algunos antecedentes históricos y la situación de los pescadores actuales.

Para cumplir nuestro propósito, en primera instancia se explica la metodología utilizada y se muestra la localización de la zona de estudio. Posteriormente se define un marco referente a adaptación y adaptabilidad para utilizarse en el contexto de la comunidad de La Palma, ubicada en la ribera del lago de Chapala. Luego se presentan los antecedentes socioambientales obtenidos de la revisión historiográfica que explican los elementos que dieron origen a la situación actual. Se muestran las transformaciones del lago que han repercutido directamente en comunidades ribereñas y en su actividad pesquera. La siguiente sección está dedicada al caso particular de la comunidad de La Palma y a las respuestas adaptativas que han implementado los pescadores y por las cuales la actividad pesquera subsiste hasta la fecha. Finalmente, el artículo termina con una discusión y unas reflexiones sobre las formas de adaptación que han resultado de las condiciones cambiantes de los niveles de agua en el lago de Chapala.

\section{Metodología}

\section{Zona de estudio y localización}

El lago de Chapala forma parte de la cuenca Lerma-Chapala, en el occidente mexicano, y se localiza entre los estados de Jalisco y Michoacán (mapa 1). Su principal afluencia proviene de los ríos Lerma y Duero, mientras que su más 
importante salida hacia el océano Pacífico es el río Santiago. Es el tercer lago de mayor tamaño en Latinoamérica y el primero a nivel nacional (Covarrubias \& Ojeda, 2009). Actualmente, el lago de Chapala tiene una extensión de 114659 ha y está clasificado como un lago tropical somero (Tereshchenko $e t$ al., 2002; Moncayo et al., 2012).

La actividad pesquera que se lleva a cabo en ese lago se sigue considerando como artesanal y de pequeña escala (Gaspar \& Hernández, 2013), debido a que se realiza de manera individual o familiar en embarcaciones de fibra de vidrio que miden $<10$ de eslora y que en ocasiones no cuentan con motor. Actualmente sus principales pesquerías son la tilapia (54\%), la carpa (34\%), y el charal (12\%).

\section{Mapa 1. Localización del lago de Chapala}
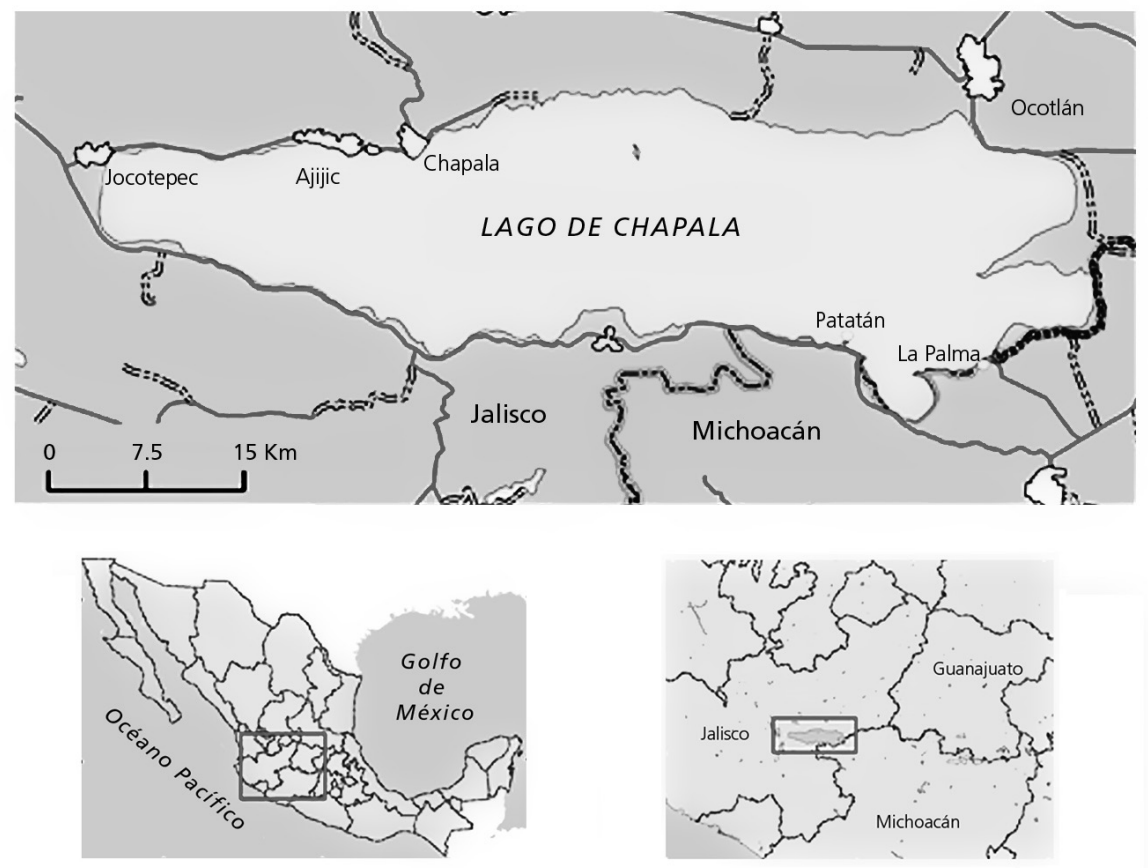

Fuente: INEGI (2012). Editado por Rosario Barrera Arumir.

Para alcanzar el objetivo de explorar las respuestas adaptativas de los pescadores ante los cambios en el medio físico y la forma en que las comunidades pesqueras han podido sobrevivir y seguir siendo parte esencial de la vida socioeconómica y cultura local, se decidió retomar el caso de la comunidad ribereña 
de La Palma. Esto porque es de las mayormente conocidas por su actividad pesquera y porque en ella se han representado históricamente las transformaciones de la ciénega de Chapala.

La comunidad de La Palma pertenece desde 1935 al municipio de Venustiano Carranza, en Michoacán; cuenta con un grado de marginación medio y 3601 habitantes. Este poblado se encuentra entre el lago y la ciénega de Chapala y sus principales actividades económicas son el comercio, la agricultura y la pesca.

\section{Trabajo de campo}

La presente investigación se llevó a cabo en tres etapas. La primera se enfocó en las fuentes de información secundaria y se basó en la revisión historiográfica y consulta de archivo para recopilar la poca información disponible sobre el municipio michoacano de Venustiano Carranza, al cual pertenece la aislada y rural comunidad de La Palma. Ello permitió un acercamiento a la relación entre la pesca, el lago de Chapala y el desarrollo de su ciénega, y reveló la importancia regional sociohistórica y económica de La Palma. Además se consultaron bases de datos estadísticas sobre los volúmenes de pesca y los niveles de agua del lago de Chapala, tanto en la oficina de la Sagarpa de Michoacán y Jalisco, como en la página de Internet de la Comisión Estatal del Agua del estado de Jalisco.

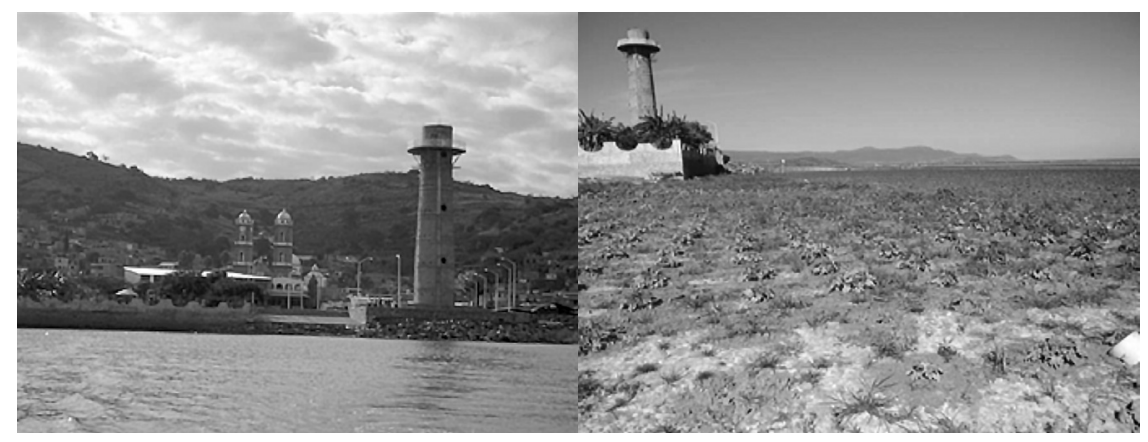

Fuente: Fotografías de Carmen Pedroza Gutiérrez y Jaime Chavolla. Izq. Lago de Chapala con un nivel de agua medio (abril de 2012). Der. Lago de Chapala en época de sequía (abril de 2013).

Las fuentes de información primaria se recopilaron en las siguientes dos etapas del trabajo de campo. Una durante los meses de abril a noviembre de 2012, correspondiente a un periodo en que la orilla del lago estaba a pocos metros del pueblo y los pescadores realizaban su actividad con cierta producción favorable. 
La segunda terminó tras varios meses de estiaje en abril de 2013, cuando se constató un drástico cambio de nivel en el lago (fotos 1 y 2). En ambas etapas se hicieron recorridos de reconocimiento en la comunidad y salidas en lancha por el lago de Chapala, observando las artes de pesca y entrevistando informalmente a los pescadores. En la segunda etapa, los recorridos se concentraron en estudiar la parcelación del terreno lacustre descubierto tras la sequía y la distancia que tenían que recorrer los pocos pescadores aún activos para llegar al agua.

\section{Entrevistas}

Se utilizaron tres tipos de entrevistas: no estructuradas, semiestructuradas y en profundidad; además se aplicó un cuestionario a pescadores con respuestas abiertas y cerradas (Bernard, 2006). Conviene confirmar que los sujetos de estudio en esta investigación son los pescadores de manera individual (Gatti, 1986) y no sus hogares. Por esta razón los cuestionarios se aplicaron individualmente en las zonas de desembarque y no en sus viviendas.

Primero se entrevistó informalmente a tres pescadores con el objetivo de conocer los lugares y horarios de desembarque, así como la estacionalidad de la actividad pesquera. Posteriormente se utilizaron entrevistas semiestructuradas para informantes clave como el jefe de Tenencia, el gerente del Distrito de Riego, algunos de los actores involucrados en la parcelación y reparcelación de La Comarca, como se ha llegado a conocer a esta zona del lago, y jefes de cooperativas. Para entrevistar al cronista de la ciudad se utilizaron entrevistas en profundidad, por ser un actor fundamental en la dinámica actual e histórica de la comunidad. Estas se llevaron a cabo para conocer el contexto sociohistórico y ambiental de la actividad pesquera en la ciénega de Chapala.

Como ya se mencionó, a los pescadores se les aplicó un cuestionario con preguntas abiertas y cerradas. En el momento del estudio había 160 pescadores registrados en las cooperativas de La Palma. El número de entrevistados fue de 36 , lo cual representa una muestra de más del $20 \%$. Cabe aclarar que el número de pescadores registrado no equivale al número total de personas que en algún momento salen a pescar, lo cual no fue posible determinar. Esto se debe a que la cantidad de personas que pescan es muy variable y, según los jefes de cooperativas locales, depende de varios factores: $a$ ) de la época del año, ya que los meses más cálidos corresponden a una mayor producción de peces y hay más pescadores que en el invierno; b) el nivel de agua, pues si este es bajo se dificulta salir a pescar; y c) el número de pescadores ilegales (sin permiso de pesca), cuya participación sería meramente oportunista, ya sea porque la temporada es buena, o porque necesitan alimentar a sus familias. Sin embargo, los pescadores registrados son 
quienes se reconocen socialmente en La Palma como tales (Montes, entrevista, 27 de enero de 2013), no solo por el reconocimiento de su comunidad local, sino porque son los que más repetidamente implantarán las estrategias de adaptación en que se interesa este artículo.

Tabla 1. Número de entrevistados

\begin{tabular}{|c|c|c|}
\hline Entrevistados & Núm. de entrevistas & Tipo de entrevistas \\
\hline $\begin{array}{l}\text { Informantes clave: } \\
\text { Jefe de Tenencia } \\
\text { Gerente del Distrito de Riego } \\
\text { Actores involucrados con la parcelación (2) } \\
\text { Jefes de cooperativas (2) } \\
\text { Cronista de la ciudad }\end{array}$ & 7 & Entrevista en profundidad \\
\hline Pescadores & $\begin{array}{c}36 \\
3\end{array}$ & $\begin{array}{c}\text { Cuestionario } \\
\text { Entrevistas no estructuradas }\end{array}$ \\
\hline Subdelegación de Pesca (Sagarpa, Michoacán) & 2 & Semiestructuradas \\
\hline Total & & 48 \\
\hline
\end{tabular}

Fuente: Carmen Pedroza Gutiérrez, con base en trabajos de UNAM PAPIIT IB300212 y UNAM Programa de Becas Posdoctorales 2013.

La información obtenida dio elementos para esbozar la situación general del lago respecto de la variabilidad de su orilla y de la pesca en cuanto a su competencia con otras actividades productivas. Asimismo, a partir de esta información se presentan los antecedentes socioambientales y sociohistóricos que originaron la situación actual del lago de Chapala para así entender mejor el contexto actual de la actividad pesquera, la cultura lacustre, las respuestas adaptativas de los pescadores y por qué la pesca sobrevive hasta nuestros días.

\section{Adaptabilidad frente a las condiciones cambiantes del medio físico}

Adaptarse a las situaciones cambiantes, a los riesgos y oportunidades que ofrece el medio físico es una actividad crucial para la humanidad. Entender las formas en que diferentes sociedades se adaptan y cuáles son las mejores soluciones o respuestas adaptativas es un reto para los científicos y quienes elaboran e implementan políticas de desarrollo.

Las capacidades y formas adaptativas desarrolladas por los seres humanos han sido estudiadas por las ciencias biológicas y sociales desde perspectivas que van de los enfoques darwinianos hasta los de la ecología cultural. Esto debido a que el término "adaptación" tiene sus orígenes en la biología evolutiva, aunque cuenta con aplicaciones aceptables para sistemas sociales a fin de explicar su dimensión cultural (Smith \& Wandel, 2006). Algunos científicos sociales han sugerido que la adaptación es "una consecuencia de seleccionar 
formas de actuar que varían a través de prácticas culturales (adaptación) las cuales han permitido históricamente a una cultura que sobreviva" (O’Brien \& Holland, 1992: p. 40). Algunos enfoques darwinianos limitan el término a una práctica cultural que surge en condiciones de estrés, pero otros reconocen que las respuestas adaptativas no se limitan a estímulos de estrés ambiental (Devenan, 1983).

La cultura y el conocimiento o las prácticas tradicionales motivan una mayor capacidad de adaptación a los cambios en el medio físico y en el acceso a los recursos naturales (Grothmann \& Patt, 2005; Smith \& Wandel, 2006). De hecho, el "aprendizaje social le permite a las poblaciones humanas acumular reservas de información adaptativa por muchas generaciones, y esto conlleva a la evolución cultural de instituciones sociales y tecnología permitiéndoles ser altamente adaptativas" (Boyd \& Richerson, 2006: p. 15). Esto convierte a dichos factores en claves para entender cómo algunas poblaciones humanas se enfrentan a las transformaciones y estresantes del medio físico. Devenan (1983) propone que la adaptación se da tal vez en respuesta a cambios ambientales físicos, demográficos, económicos u organizacionales.

Para entender los fenómenos adaptativos es útil reconocer su objetivo sociocultural de reproducción social, que en medios específicamente rurales se identifican por sus características colectivas y frecuentemente familiares. Mummert (1994) incluso ha determinado que las acciones de adaptación se centran en la unidad doméstica.

Las respuestas adaptativas que más interesan en este artículo cumplen dos condiciones iniciales. Se deben a cambios en el ambiente físico y son generadas socioculturalmente por el sujeto pescador —entendido como categoría social: individuo que se reconoce y determina por la actividad ejercida, la pesca (Gatti, 1986) - . Si asumimos que nuestro objeto de estudio, el pescador, se compone de sectores primordialmente interactivos y dependientes del lago de Chapala, destaca una perspectiva que rebasa la económica y organizacional y estipula que las estrategias de adaptación siempre buscarán máximas ganancias monetarias. Al contrario, como lo aclara Macken (2009: p. 45), las identidades rurales como las de los agricultores tradicionales y pescadores artesanales, son indisociables de sus actividades productivas. Esta relación intrínseca entre identidad personal y tradición familiar privilegiará la reproducción sociocultural sobre la racionalidad económica, incluso en situaciones de estrés ambiental (OECD, 2007).

Las respuestas adaptativas se manifiestan de diferentes formas dependiendo de la escala (individual, grupal, global), el periodo de tiempo (rapidez) en que ocurre el fenómeno en cuestión y los actores participantes (Smith $\&$ Wandel, 2006). 
Estos factores orientarán la adaptación como reactiva o proactiva, según el momento en el que ocurre; o bien como pública o privada, dependiendo de quién se adapta (Smith et al., 2000). Según Klein (1998), la primera dimensión (adaptación reactiva) se refiere al tiempo de la adaptación, a si es motivada por predicciones de un evento que ocurrirá en un tiempo indeterminado en el futuro, como una adaptación espontánea. La segunda (adaptación proactiva) es un proceso planeado que pasa por diferentes etapas de concientización, diseño, implementación, monitoreo y evaluación (Grothmann \& Patt, 2005). La orientación privada se refiere a actores privados (por ejemplo, agricultores o pescadores) (Klein, 1998), mientras que la pública sería parte del desarrollo de políticas e incluye cuatro pasos: identificación de qué se va a adaptar, evaluación, decisión y respuesta, y retroalimentación (Risbey, Kandlikar \& Dowlatabadi, 1999). En otras palabras, una respuesta adaptativa reactiva podrá presentar elementos espontáneos de reacción ante un suceso imprevisto, o que sabemos que ocurrirá, pero no en qué momento. En cambio la adaptación proactiva podrá ser la respuesta planeada y organizada de un grupo de actores ante un suceso identificado. Sin embargo, en ambos casos el enfoque de la respuesta tendrá como base los conocimientos y prácticas socioculturales de quienes las llevan a cabo (Grothmann \& Patt, 2005).

En el presente artículo nos concentramos en las respuestas adaptativas privadas, reactivas o proactivas, referidas a las de los pescadores ante los cambios en el ambiente físico. Estos cambios se relacionan con las fluctuaciones naturales o inducidas en el nivel de agua del lago de Chapala, cuestión en donde se debe considerar que los lagos someros tropicales, como es el caso, se caracterizan por sus fluctuaciones en el nivel de agua cuya amplitud depende de las características climáticas de cada región (templado, semiárido, árido) y de los usos humanos (Coops, Beklioglu \& Crisman, 2003: p. 24). Se ha demostrado que estos factores alteran de manera radical el estado de los lagos someros y por lo tanto la actividad pesquera que se practica en estos ecosistemas (Sarch \& Birkett, 2000; Moncayo et al., 2012). Ante las oscilaciones en los niveles de agua, las comunidades lacustres tienen que responder según los lagos se contraigan o se expandan.

\section{Antecedentes socioambientales y transformaciones del lago de Chapala}

Para entender la situación actual y cómo el conocimiento adquirido por generaciones y prácticas tradicionales han motivado la capacidad actual de los pescadores para seguir practicando la pesca en La Palma, es importante conocer el contexto histórico en que esta se ha desarrollado, así como los factores que la han venido transformando. Como ya se dijo arriba, las variaciones en 
el nivel del lago son multifactoriales y coyunturales con los sucesos de sus épocas, que influyen en las estrategias de los pescadores de oficio. Elementos como la presencia o ausencia de intermediarios, legislaciones agrícolas y economías regionales e internacionales cambian, y son necesarios para entender la temporalidad que estudia este artículo.

\section{El lago de Chapala y la pesca en el desarrollo regional histórico}

Gran parte de la situación actual del lago de Chapala y de su actividad pesquera se explican partiendo de la desecación que experimentó entre 1904 y 1908. La modificación lacustre se inserta en el modelo de desarrollo nacional del Porfiriato y de algunos gobiernos posteriores (Boyer, 2007) que buscaban reproducir la modernidad y el progreso proclamado por los antiguos y nuevos imperios occidentales con todas las limitantes involucradas. Esta visión confió el desarrollo rural a la hacienda como núcleo de producción, centrado en actividades terrestres como la agricultura y la ganadería. Por esta razón se desecó una tercera parte del lago de Chapala, así se aprovecharía la zona pantanosa y de difícil navegación para dichas actividades productivas.

Sin perder de vista que el objetivo de aquella época era modernizar e industrializar el país, estas acciones vistas en retrospectiva nos muestran algunos de los orígenes de los problemas actuales que abordamos en este artículo.

Así, bajo el marco de dicho modelo, los grandes hacendados buscaban incrementar sus extensiones de tierra para la producción de ganado y la agricultura. Una forma de hacerlo fue desecando ecosistemas de ciénega o lagunares en la región. ${ }^{2}$ Primero fue la ciénega de la laguna de Zacapu hacia 1900 y poco después la de Chapala (Mummert, 1994).

Los promotores de estas operaciones fueron los grandes hacendados. Desde el siglo XVII, la consolidación y ampliación de sus haciendas requería de grandes extensiones de tierra para la ganadería. Los hacendados buscaron satisfacer esta necesidad apropiándose permanentemente de las planicies expuestas durante épocas de estiaje en el lago de Chapala (Paré, 1989).

A pesar de que el fomento pesquero no se encontraba dentro del bagaje cultural-productivista de los hacendados, en los cuerpos de agua continentales se introdujeron especies exóticas, lo que daba continuidad al modelo productivista importado. De hecho, en 1889 la Secretaría de Fomento del gobierno

2 Este modelo productivista, que implica desecar ecosistemas lagunares para la producción agrícola, no se da solo en Michoacán, sino también en otras partes del país. Como ejemplos podemos citar la desecación de la laguna de Mayrán y la de Viesca en el estado de Coahuila (Wolfe, 2013). 
porfirista sembró variedades foráneas de peces para captura como la trucha arcoíris y la carpa asiática. Dentro de este mismo contexto, en 1892 se sembraron cinco mil ejemplares en Michoacán (Carranza, 1953). Esto fue con la intención de iniciar una industria piscícola en el país y de abastecer con alimentos sanos y nutritivos a los campesinos. Además, Porfirio Díaz veía la pesca de captura continental como una actividad deficiente, mientras que consideraba que la piscicultura daría oportunidad para crear nuevas industrias más productivas (Contreras, 2012).

Los principales beneficiarios de la desecación de Chapala fueron las grandes haciendas ganaderas regionales que, al mismo tiempo, fueron los primeros agentes que buscaron sustituir la actividad pesquera en esta región. La desecación vino acompañada de la demanda laboral en los campos productores de granos para el ganado, lo cual empezó a redirigir la población lacustre hacia el peonaje (Montes \& Montes, 2008).

Posteriormente, la construcción del bordo de contención generó miles de empleos para cargar piedra y sacos de lodo (Montes, 1991), y eliminó la condición ribereña de varias comunidades de forma permanente. No sería sino hasta que llegaron los desarrollos tecnológicos a finales del siglo XIX que se pudieron superar los deficientes bordos improvisados de piedra y lodo que constantemente necesitaban reemplazarse. Estos acontecimientos provocaron que cada vez menos localidades se identificaran como pescadoras, quedando como recuerdo los tiempos en que expediciones de pesca y actividades derivadas rendían suficiente para ocupar "ejércitos" (Ortiz, 2001: p. 12). Décadas después, encontramos que las aproximadamente cincuenta mil ha desecadas continúan beneficiando a la agricultura y afectando trascendentalmente el lugar de la pesca y de la cultura pesquera en esta región.

Ejemplo de estas afectaciones es la migración de pescadores. Durante la Colonia y el Porfiriato, la extensión de pastizales por despojo de tierras (De Lameiras, 1985) y por desecación natural e intencional obligó a varias comunidades pesqueras a reubicarse en las cercanías para continuar con su actividad (Montes, entrevista, 27 de enero de 2013). Sin embargo, estos poblados espontáneos y mal posicionados — solo recordados por la historia oral— ahora son inexistentes. ${ }^{3}$ No obstante, la estrategia se repitió de manera permanente durante una prolongada sequía a mediados del siglo xx con la fundación de Petatán a aproximadamente treinta kilómetros de La Palma. Esta estrategia adaptativa de

3 Algunos de estos pueblos decimonónicos, ahora desaparecidos, incluyen Las Candelas, que estaba cerca del actual Puerto de León; la isla del Sauz, en la cercanía de Sahuayo, y Boca del Río que, según cronistas, fue uno de los más fugaces de todos, con tan solo seis meses de existencia (Montes, entrevista, 27 de enero de 2013). 
desplazamiento podría considerarse como antecedente de las futuras tendencias migratorias que ahora caracterizan la región (De Lameiras, 1985). Pero lo más importante es reconocer que fue facilitada, en gran parte, por la condición nómada y la fidelidad de los pobladores a su oficio tradicional: la pesca.

Con excepción de Petatán, que emergió después, estos refugios tempranos de actividad pesquera, aun durante su limitada supervivencia, alcanzaron un breve aliento de prosperidad. Para la segunda mitad del siglo xIx y las primeras décadas del xx, nuevamente impulsado por el desarrollo tecnológico, el interés por el lago creció. Esta vez no por su utilidad ganadera o agrícola, sino por los transportes que inicialmente compaginó con la pesca como motores de desarrollo en diferentes niveles socioeconómicos.

Así, en 1868 la región se vio transformada socioeconómicamente de manera temporal por la introducción de barcos de vapor al lago de Chapala. Varias empresas grandes y pequeñas de transporte y productivas se articularon convirtiendo a La Palma en "el puerto de mayor importancia en Michoacán" (Montes \& Montes, 2008: p. 1). Gracias a esta actividad, entre 1868 y 1929 esta parte de la ciénega de Chapala se convirtió en un eje de desarrollo regional. Según algunos historiadores, las flotillas de canoas independientes que atendían la demanda no absorbida por los vapores no cabían en el muelle (Montes, 1991). Regionalmente, la pesca se articuló como una industria completa con pescadores, fileteadores, ensaladores, fabricantes de canoas, arrieros y otros transportistas. Además, existen indicios que llevan a pensar que la pesca en estos años contaba con suficiente fortaleza como para incluso resistir inicialmente las leyes dictadas por Porfirio Díaz, que intentaban regularla (Ortiz, 2001).

Sin embargo, el impulso y auge de las actividades lacustres no fueron permanentes. Empezando por las mencionadas leyes porfiristas que impusieron vedas, requerimientos de licencias y de concesiones disminuyeron la fortaleza inicial de los pescadores. Las autoridades porfiristas y locales se corrompieron gradualmente y se coludieron, lo cual elevó los costos para los pescadores (Ortiz, 2001). Por otra parte, la construcción de la carretera Guadalajara-México, entre 1929 y 1935, sustituyó la necesidad de vapores y La Palma dejó de ser puerto (Montes $\&$ Montes, 2008).

Sin menospreciar los factores históricos que llevaron al cese del desarrollo chapálico en Michoacán, es de notar que el auge de la pesca y de las comunidades pesqueras en y alrededor de La Palma fue secundario a los intereses del transporte $y$, en cierta forma, solo aparente. Cronistas locales aluden a que la parte importante de la pesca se asociaba con el turismo que pasaba en los barcos de vapor (Montes \& Montes, 2008). Además, La Palma enfrentaba la competencia progresivamente mayor de otras comunidades pesqueras. Puertos como Ocotlán y Chapala, ambos en el estado de Jalisco, se desarrollaron más 
rápidamente, permitiendo a sus comunidades pesqueras mayor consolidación (Burton, 2008).

Cabe subrayar que este contraste en grados de consolidación entre riberas estatales es trascendental. La industria de vapores y la concatenación de actividades no generaron beneficios a largo plazo para las localidades michoacanas. De hecho, actualmente en La Palma no existen siquiera vestigios materiales de la intensa actividad que hospedó (Burton, 2008; Montes, 1991). El poco y fugaz desarrollo infraestructural logrado fue insuficiente para que las comunidades se adaptasen a nuevos escenarios económico-políticos. Ello se hace visible en las oleadas de pobladores, incluidos pescadores, que han abandonado la región a partir de las tendencias migratorias que empezaron hacia mediados de siglo con el programa Bracero (1942-1964). Michoacán sería el tercer estado en enviar el mayor número de trabajadores (Fernández, 2011).

Es posible afirmar que después de la desecación intencional del lago en 1904 los retos más importantes para la pesca se dieron a partir de la época revolucionaria. Los factores político-económicos son de particular interés, tal es el caso del desmembramiento de las grandes haciendas y la creación de ejidos durante las décadas de los veinte y los treinta (Covarrubias, 2007). La distribución de tierras y la formación de una clase masiva de agricultores fueron acompañadas por la creación de la Secretaría de Recursos Hidráulicos (SRH, 1946-1976) en 1946. Esta institución incentivó el uso del agua para fines agrícolas a través de grandes obras de irrigación como presas y pozos. Con ello se hizo evidente la concepción federal sobre la pesca de captura continental como un obstáculo para otras actividades productivas, como la ganadería y la agricultura, lo cual amenazó nuevamente su desarrollo y supervivencia.

Estos hechos muestran una visión gubernamental de incompatibilidad entre los usos del lago, entre la ganadería y la agricultura, por una parte, y la pesca de captura por otra. Dicha incompatibilidad fue generalizándose entre la misma población local y regional. De hecho, cada vez que desciende el nivel del lago, surgen interesados en sembrar las tierras que se van descubriendo. Esta tendencia por ganarle tierra al lago de Chapala se intensificó a partir de 1941, cuando el gobierno federal comenzó a concesionar esos terrenos a particulares (Paré, 1989). Con el tiempo y tras repetidas exposiciones, las tierras de debajo del lago se han hecho bien conocidas por los pobladores lacustres.

\section{La variabilidad física del lago de Chapala}

Actualmente, el lago se extiende sobre poco más de $1100 \mathrm{~km}^{2}, 114659$ ha, según CEA (2013). Una característica destacada que forma parte de su naturaleza 
como lago tropical somero son las fluctuaciones en su nivel de agua, radicalizadas por las actividades humanas y que además rompen con sus ciclos naturales.

A más de un siglo de su desecación parcial inducida, continúa sufriendo transformaciones físicas que mantienen a comunidades lacustres, como La Palma, en continua alerta para poder responder a las fluctuaciones en el nivel de agua del lago.

Según Paré (1989), desde la Colonia hasta 1940 las extracciones de agua fueron menores a las aportaciones, por lo que se observa que las oscilaciones del lago en esa época se debieron más bien a fenómenos naturales y climatológicos. Sin embargo, después de esa fecha las actividades antropogénicas resultan en extracciones insostenibles.

La extracción masiva de agua se debe, en parte, a que actualmente el lago de Chapala es la principal fuente de suministro para la zona aledaña y metropolitana de la ciudad de Guadalajara. El área abastecida representa un 60\% de los habitantes de esta ciudad, lo que equivale a 2.4 millones de personas, para quienes se extraen $5.4 \mathrm{~m}^{3} / \mathrm{s}$ (SIAPA, 2013).

Además de lo anterior, la evaporación posiblemente sea el factor natural que más afecta los niveles de agua del lago. Se calcula que llega a ser de aproximadamente $10 \mathrm{~mm}$ por día durante los meses de marzo a mayo (Tereshchenko et al., 2002). Las oscilaciones del lago de Chapala también están en relación directa con las descargas del río Lerma. Tereshchenko et al. (2002) demuestran que los periodos de descenso del agua son precedidos por años de bajas descargas de este afluente. Igualmente, que niveles altos coinciden con años de mayor afluencia del río Lerma. Aparicio (2001) señala que de 1922 a 1969 la afluencia del río Lerma fue de $1646 \mathrm{hm}^{3}$, y entre 1970 y 2001 fue de $738 \mathrm{~mm}^{3}$. Esto se debe a que gran parte del agua que deja de llegar a Chapala se queda en los sistemas de irrigación de las 552 presas que se encuentran distribuidas a lo largo de la cuenca, lo cual además de disminuir el volumen del agua causa modificaciones en sus flujos, alterando su biodiversidad (Cotler \& Gutiérrez, 2005).

Fenómenos naturales como El Niño y el cambio climático se manifiestan en la variación de los niveles de precipitación pluvial que, según Tereschenko et al. (2002), han sido de 500 a 1000 mm de lluvia. Por su parte, Aparicio (2001) afirma que entre 1922 y 1962 el promedio de precipitación anual fue de 706 mm, y entre 1970 y 2001 de $697 \mathrm{~mm}$.

Las continuas variaciones también se observan en datos recientes. En 2013 el lago estaba $1.45 \mathrm{~m}$ por debajo de su nivel anual anterior, lo que fue el cambio más drástico en los últimos diez años (CEA, 2013). De acuerdo con el SIAPA, en contraste con 2012, Chapala tuvo una recuperación de tan solo $0.49 \mathrm{~m}$. Como se observa en la gráfica 1 , frecuentemente los descensos son mayores a su volumen de recuperación. 


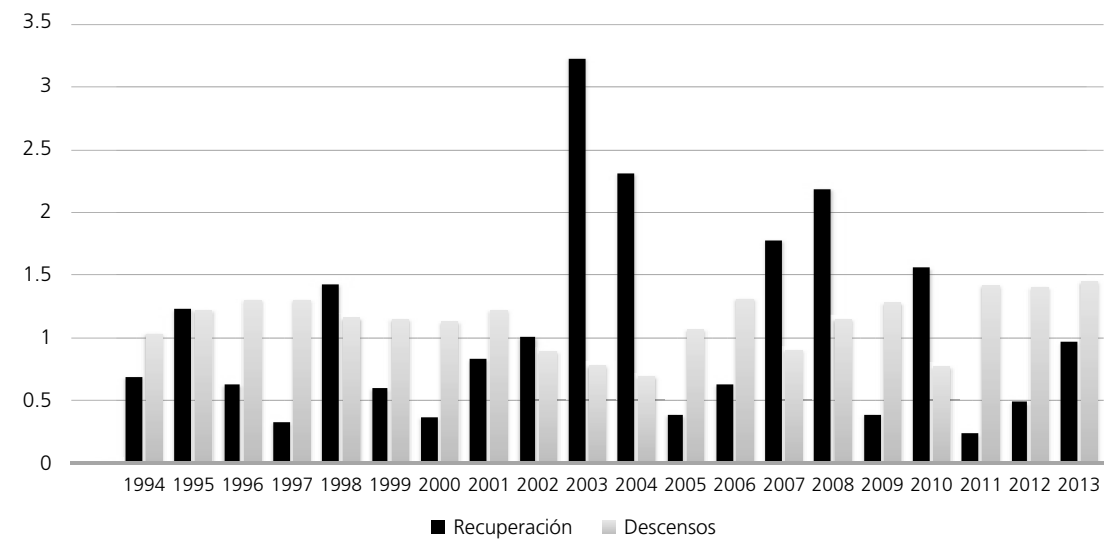

Fuente: Comisión Estatal del Agua (CEA) de Jalisco (2013)

Este tipo de factores externos afecta directamente los niveles de captación del lago y, como se verá en el siguiente apartado, al ecosistema lagunar y la actividad pesquera.

Factores estresantes en el lago de Chapala y su repercusión en la actividad pesquera

Hoy día la pesca tiene que enfrentar las problemáticas relativas al cuerpo de agua y además las inherentes a la actividad misma. Por una parte, está la concentración de contaminantes y la extracción de agua que modifican el volumen y la calidad del líquido en el lago. Por otra, el sobreaprovechamiento, la pesca ilegal y la introducción de especies exóticas, que alteran las poblaciones endémicas explotables.

Uno de los factores más importantes que afecta a la fauna local es la contaminación del río Lerma. Este acumula azolve y desechos en su recorrido de más de $700 \mathrm{~km}$ desde el valle de México y por el centro del país, pasando por miles de sitios de actividad industrial (Mestre, 1997). Según algunas estimaciones, entre 1930 y 1977, el Lerma vertió en Chapala alrededor de 78 millones de metros cúbicos de azolve provenientes de tierras deforestadas (Covarrubias \& Ojeda, 2009). El estrés por contaminantes se agudiza por la extracción. Existen estudios que han encontrado contaminantes orgánicos, metales pesados y plaguicidas, cuya concentración varía según lo hagan los niveles de agua (Hansen 
\& Van Afferden, 2001; López, Ramos \& Carranza, 2007), lo cual afecta el inventario de fauna lacustre (Moncayo et al., 2012), de por sí ya amenazado por la sobrepesca y la competencia de especies exóticas.

La sobrepesca se evidencia cada vez más del lado michoacano en los disminuidos volúmenes y tamaños de ejemplares de captura. Esto coincide con los volúmenes de captura señalados por la Sagarpa (gráfica 2), los cuales muestran descensos importantes en los últimos años.

Gráfica 2. Volumen de captura pesquera del lago de Chapala (2000-2012)

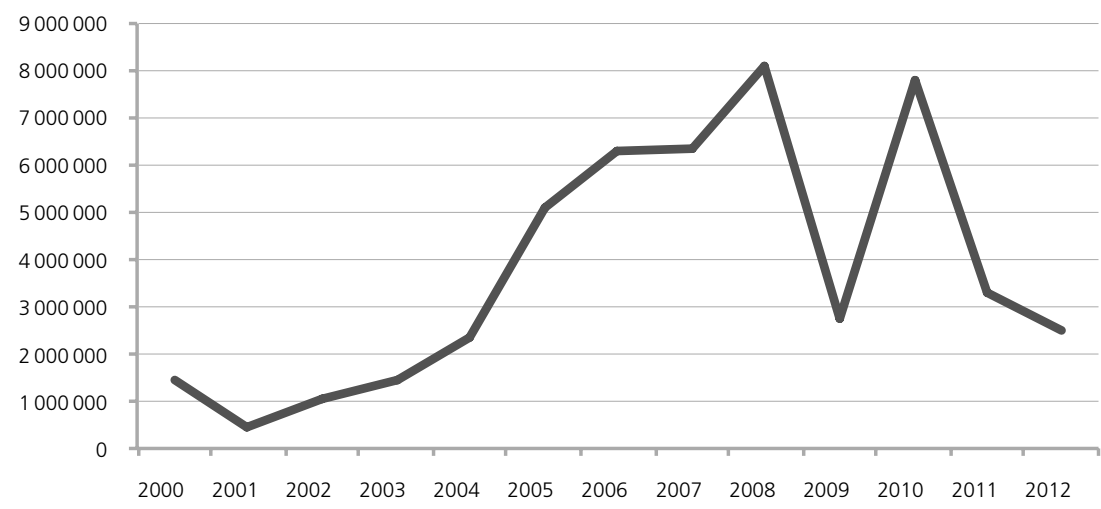

Fuente: Sagarpa Jalisco (2012), Sagarpa Michoacán (2012).

Además, como lo señala la gráfica 3, mientras que el número de artes de pesca aumenta, el volumen de captura disminuye, lo cual sería un indicador de sobrepesca. Por otra parte, en la gráfica 4 se observa cómo el volumen de captura se modifica conforme aumenta o disminuye el nivel del agua en la mayoría de los casos.

A los problemas de contaminación, extracción y sobrepesca se suma la reducción poblacional de peces nativos — como el pescado blanco- que se intensifica con la competencia de especies introducidas. Casos relevantes en Chapala son la carpa asiática y la tilapia africana, ambos de menor valor comercial que el pescado blanco. Dichas especies se introdujeron en los cuerpos de agua continentales por todo el país a finales del siglo XIX y a mediados de la década de 1960, respectivamente. La introducción de especies exóticas ha afectado negativamente a las poblaciones de peces nativos. La carpa aumenta la turbidez del agua y eventualmente introduce parásitos que dañan a otras especies (Okolodkov et al., 2007). La tilapia, por su parte, al ser de alta fecundidad y rápido crecimiento, compite 
por espacio y alimento con otros peces (Wicki \& Gromenida, 1998). Además, ambas especies son de rápido crecimiento y adaptación, factores por los cuales han superado a las especies nativas (Moncayo et al., 2012).

Gráfica 3. Estimación de la captura por unidad de esfuerzo (ECPUE) anual en toneladas por arte de pesca en diferentes años de la pesquería del lago de Chapala

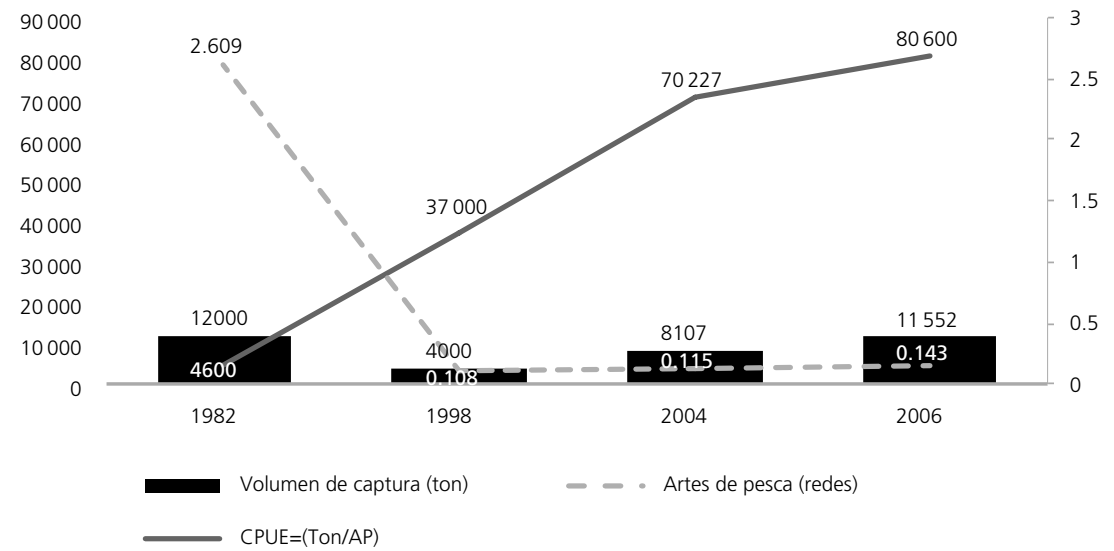

Fuente: Elaboración propia con datos de Arredondo-Vargas et al. (2013) y Carta Nacional Pesquera (2006).

Gráfica 4. Volumen de captura (ton) y niveles de agua en el lago de Chapala

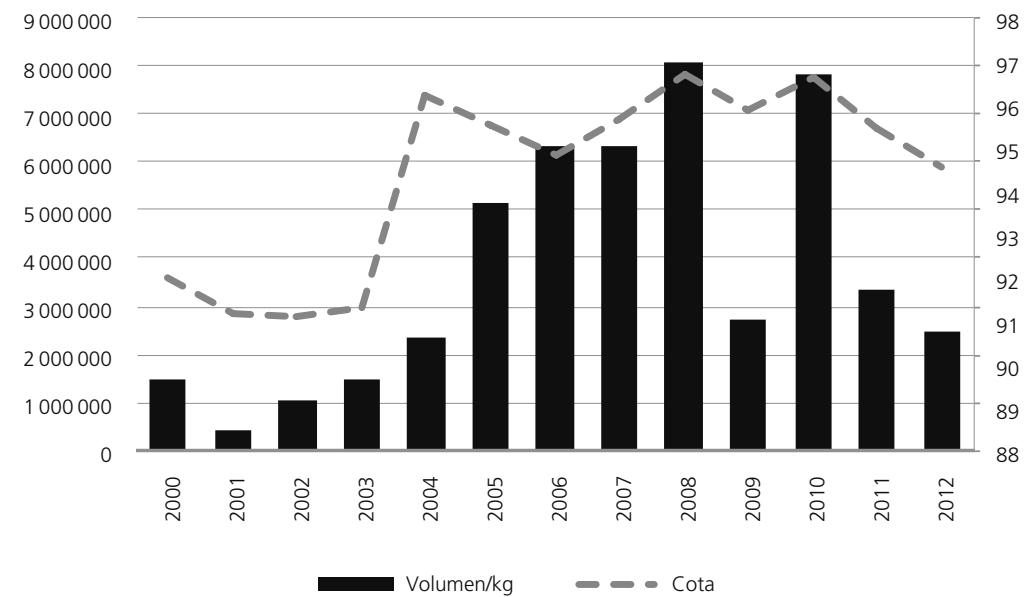

Fuente: Elaboración propia con datos de Sagarpa (2012) y Comisión Estatal del Agua Jalisco (2013). 
Como se deduce, existe una urgencia por el riesgo de desaparición que corre el pescado blanco (de la familia Atherinidae del género Christoma), endémico de la cuenca Lerma-Chapala, en su sistema Chapala-Cuitzeo-Pátzcuaro (Covarrubias \& Ojeda, 2009). Pero existen otros casos también: "Han desaparecido en el lago peces como la popocha, el boquinete, la sardina, la lisa, la barbeta y la lobina y disminuido notablemente la población de pescado blanco, charales y bagres nativos" (Paré, 1989: p. 65). Sumado a esto se registra en el Anuario Estadístico de Acuacultura y Pesca de la Sagarpa que el volumen de captura de pescado blanco no se contempla en las estadísticas de forma individual desde 1990 por no ser representativo.

Esto muestra la relación entre la problemática ambiental del lago y los factores inherentes a la pesca (sobrepesca, pesca ilegal e introducción de especies exóticas).

Con base en lo anterior es posible cuestionar si la introducción de especies exóticas como la tilapia y la carpa aporta más a la supervivencia o al deterioro de la cultura pesquera. Su introducción y la consecuente escasez de poblaciones endémicas han empobrecido tradiciones locales basadas en especies como el pescado blanco. Más que un producto, esta especie ha sido un referente cultural y gastronómico en las regiones lacustres michoacanas. Su puesta en riesgo no debe entenderse solo como un indicador de deterioro ecológico, sino como un determinante de pauperización económica.

\section{La comunidad ribereña de La Palma, adaptación cultural y permanencia de la actividad pesquera}

El pueblo de La Palma fue una estancia ganadera de dimensión considerable y el puerto más activo de Michoacán. Es de destacar que, a pesar de todos los factores expuestos, ya sea inducidos por la mano del hombre o naturales, la pesca en el lago de Chapala ha logrado sobrevivir. Algunos incluso consideran la actividad pesquera en La Palma como la más importante en aguas continentales del estado (Castellanos, 2011). En esta sección se aborda tanto la problemática que enfrentan los pescadores de La Palma, como sus estrategias adaptativas y razones para continuar pescando.

\section{Problemática identificada por los pescadores}

En La Palma se evidencian los problemas referentes a las condiciones y naturaleza del lago, y los inherentes al sector pesquero. En este sentido, los pescadores 
respondieron que los problemas más importantes del lago son la sobrepesca, la contaminación y las descargas residuales. Y perciben diferentes impactos negativos en los problemas mencionados (tabla 2).

Tabla 2. Problemática del lago de Chapala, según los pescadores

\begin{tabular}{lll}
\hline Problemática & Respuestas de los pescadores & $\%$ \\
\hline Sobrepesca (47\%) & Red mangueadora y charalera (ancho de malla) & 6 \\
& Hay menos pescado & 28 \\
& Se llevan la mojarra chica (se acaban las crías) & 11 \\
& No hay ingreso & 2 \\
Contaminación (36\%) & La gente cree que el pescado está contaminado & 8 \\
& Se enferma el pescado & 6 \\
& Arden los ojos & 6 \\
& Baja el precio & 8 \\
Descargas (17\%) & Mal olor y sabor del pescado & 8 \\
& El pescado se va a lo limpio & 11 \\
Total & Matan el pescado & 6 \\
\hline
\end{tabular}

Fuente: Carmen Pedroza Gutiérrez.

De acuerdo a lo expresado por los pescadores en las encuestas, la problemática principal es la sobrepesca, causada por artes como la red mangueadora y charalera. En el caso de la primera el ancho de malla es menor al legal y la segunda está prohibida. El impacto de estas acciones se refleja en la disminución en el volumen de captura y de los ingresos. Los pescadores aseguran que la producción diaria hace tres años fácilmente rebasaba los $70 \mathrm{~kg}$; el pescador que declaró mayor volumen durante las entrevistas para este estudio apenas llegaba a los $15 \mathrm{~kg}$.

La contaminación y las descargas residuales también fueron reconocidas como problema e identificadas como factores que les afectan directamente como pescadores. A la contaminación se le atribuye una lama que se forma en la superficie del agua, que despide mal olor y que, en caso de caerles en los ojos, les provoca irritaciones. Además de que esto ocasiona que las redes se enlamen y que los peces no se acerquen a ellas. Sin dejar de mencionar el mal olor y sabor que en ocasiones tiene el pescado. Esto tiene como resultado que el consumidor rechace el producto pensando que está contaminado. A las descargas residuales se le atribuye la ocasional mortandad de peces.

Una problemática evidente pero no mencionada por los pescadores es la introducción de especies exóticas, y la consecuente cercana extinción del pescado blanco que también afecta sus ingresos. Si bien los pescadores entrevistados para este estudio confirman la reducida pero continua existencia de algunas de estas especies, a la vez aseguran que ya no es posible obtener volúmenes rentables de captura. Además de que la carpa y la tilapia son especies de bajo valor 
comercial. En el momento del estudio, los intermediarios pagaban a cinco pesos el kg de carpa o tilapia. El sNim 2014 reporta un precio de 27 pesos por $\mathrm{kg}$ de tilapia chica de Michoacán, mientras que Rojas \& Sasso (2005) señalan que en 2005 el kg de pescado blanco se vendía en doscientos pesos en las plazas de Pátzcuaro y Zirahuén. Por nuestra parte, en los avisos de arribo del año 2000 al 2012 encontramos registros de pescado blanco a precios de entre 50 y 130 pesos por kilogramo.

Aunado a esto, la falta de recursos de los pescadores en La Palma para conservar, procesar y transportar el pescado les dificulta agregar valor a su producto e insertarse en los mercados y circuitos de distribución estatal e interestatal. Esta es una actividad llevada a cabo por acaparadores. En La Palma se observan algunos acaparadores que filetean el pescado antes de entregarlo a otros que lo llevan a mercados urbanos, en particular de la ciudad de Guadalajara, ya que la mayor parte se destina a molerse para ceviche o prepararse como pescado empanizado. Sin embargo, quienes obtienen mejores ganancias son los intermediarios que venden el pescado en Guadalajara no los de La Palma, y mucho menos los pescadores.

Otra problemática no mencionada por los pescadores son las variaciones en el nivel de agua del lago, provocadas ya sea por falta de lluvia o por el reducido volumen de agua que entra por su afluente principal, el río Lerma. Esto, como ya se mencionó, ha llegado a ocasionar bajos volúmenes de agua, o incluso que grandes extensiones del lago queden descubiertas reduciendo los espacios de pesca.

\section{Estrategias de adaptación}

Siendo la pesca una actividad importante y de tradición en La Palma, transmitida generacionalmente, los pescadores antes que cambiar de oficio buscan la manera de hacer frente a los factores que afectan esta labor. En el trabajo de campo se identificaron algunas de las formas en que los pescadores responden a esa problemática (tabla 3 ).

El bajo valor de las especies introducidas con respecto al pescado blanco afecta directamente el ingreso familiar e incentiva la sobrepesca, ya que se intenta compensar el bajo precio y equilibrar los ingresos tratando de incrementar los volúmenes de captura. Para hacerlo se han implementado artes de pesca como la red mangueadora. Esta red sustituyó al chinchorro a raíz de su prohibición en 1985. ${ }^{4}$ El problema de utilizar dicha herramienta, al igual que la charalera, es que

4 A pesar de que el chinchorro se prohíbe en 1985, pescadores de algunas comunidades como Jamay en Jalisco lo siguen utilizando. Sin embargo, no es una característica del lado michoacano. 
el ancho de malla es menor al legal, lo cual empuja la estrategia de adaptación hacia la ilegalidad. Aunque esta acción sea conveniente en el plazo inmediato para el pescador, en el mediano incentiva la sobrepesca y la escasez. Un ancho de malla más pequeño incentiva la pesca de juveniles, se afecta la pesquería y se resta competitividad al producto del lago, ya que por tamańo y presentación se le asignan precios más bajos que a las especies importadas o provenientes de la acuacultura. Los pescadores argumentan que: "la necesidad nos hace que pesquemos con aquella malla para sacar de comer, si no, no comemos nada" (Jesús Gutiérrez, entrevista, 5 de septiembre de 2013).

Tabla 3. Respuestas adaptativas

\begin{tabular}{llll}
\hline Condiciones del lago & & Actividad pesquera & \\
\hline Problema & Estrategia & Problema & Estrategia \\
\hline Niveles de agua & -Migrar & Sobrepesca y pesca & -Se trata de incrementar el \\
& -Seguir el agua & ilegal & $\begin{array}{l}\text { volumen } \\
\text { - }\end{array}$ \\
& -Pescar en zonas más pro- & & -Red mangueadora más pequeño \\
& fundas & & -Pescar sin motor para reducir \\
Contaminación & -Sembrar & costos \\
& -Lavar el pescado & Especies introducidas & -Filetear para ceviche o pesca- \\
& -Lavar las redes & (bajo precio) & do empanizado \\
Descargas residuales & -No hubo respuestas & & -Venta local \\
\hline
\end{tabular}

Fuente: Carmen Pedroza Gutiérrez.

Las especies introducidas también han obligado a la comunidad a rediseñar canales de distribución y a filetear el pescado, ya que la demanda en los mercados urbanos de Guadalajara por un pescado barato para la preparación de ceviche o empanizado ha dado cabida a la carpa y la tilapia. Podría decirse que presentar la tilapia y carpa fileteadas, o molidas, ha sido la forma en como se han podido introducir en los mercados urbanos, ya que originalmente la popocha se vendía seco-salado, y el pescado blanco fresco-abierto (corte de mariposa).

En otras palabras, este pescado se vende porque es barato y porque se le considera apropiado para preparar ceviche. Además de esto los acaparadores de La Palma venden una parte en la comunidad, en este caso como el cliente lo pida: eviscerado, rayado o papaloteado (mariposa). De esta forma los ingresos para estos intermediarios son mayores ya que el kilogramo se llega a vender hasta en 25 pesos. Sin embargo, la demanda del mercado local es muy reducida, y lo que es evidente es que en La Palma los pescadores no han logrado romper la tradicional cadena de distribución organizada y controlada por los acaparadores, ya que el 95\% de los entrevistados reportó vender su producto a los intermediarios por no contar con vehículos para transportarlo. 
En cuanto a las variaciones en los niveles de agua, las estrategias identificadas fueron sobre todo la migración, o seguir el agua. Aunque el refrán popular de "la canoa sigue al lago" determinó por mucho tiempo algunos casos de migración regional, durante el siglo xx y por lo menos hasta los primeros ańos del XXI, esta estrategia se separó de la actividad pesquera y se internacionalizó. Indicadores estatales muestran que largas sequías coinciden con importantes oleadas migratorias. Por ejemplo, la sequía de 1955 coincide con momentos "cuando se enganchan más trabajadores al programa Bracero" ${ }^{5}$ para trabajar en Estados Unidos (Gil, 2009: p. 35). Otro caso es el de 1982, cuando el agua del lago dejó descubierta una gran extensión de tierra. Ortiz (2000) afirma que en este periodo emigraron 63 de los pobladores de La Palma. Una sequía similar a la de 1955 ocurrió entre los ańos 2000 y 2003. En las entrevistas realizadas, $77 \%$ de los pescadores afirmó haber emigrado en una, dos o hasta tres ocasiones a Estados Unidos porque "se secó la laguna" o porque "no había pesca".

Los pescadores que no migraron (33\%) siguieron diferentes estrategias como seguir el agua o combinar la pesca con la agricultura en la superficie descubierta. Sin embargo, como lo afirma el cronista del pueblo, "ellos siguen pescando aunque esté la laguna lejos", además de que "andan aquí y allá y si la laguna vuelve, vuelven a la pesca" (Gabriel Montes, 27 de enero de 2013). Es decir, los pescadores que se quedan siguen buscando la manera de seguir el agua para poder pescar, y tratan de complementar sus ingresos con otras actividades económicas como la agricultura.

En La Palma el área que más frecuentemente - y cabe decir, progresivamente- se descubre por sequía se conoce como La Comarca. Esta área de propiedad federal está distribuida entre las familias de la región. La forma de otorgar o conservar las concesiones registradas obedece más a usos y costumbres locales que a reglamentaciones oficiales. Históricamente, las reparticiones y sus cambios se han registrado en mapas caseros (mapa 2) y en otros oficiales, de manera que cada vez que baja el nivel del lago la comunidad se reorganiza para reclamar las tierras descubiertas y sembrar. Si bien el sector pesquero local puede condicionarse a estos escenarios de sequía y estiaje como estrategia de adaptación, su oficio permanece amenazado con bordos no oficiales construidos durante esas épocas que obstaculizan el reabastecimiento del lago en épocas de lluvias.

Otro dato interesante aportado por los pescadores es que cuando llegó el agua en 2004, el hecho fue tan rápido y repentino que no les dio tiempo a todos los que sembraron para cosechar. Durante los primeros días, con el llenado del lago, se les pagó por pescar los cultivos que salieran a flote, lo cual les generó

5 El programa Bracero estuvo vigente entre 1942 y 1964, época que coincide con la sequía de 1955, registrada como la peor del siglo xx en el lago de Chapala (CEA, Jalisco).

110 - C. Pedroza Gutiérrez, J. Chavolla | Conviviendo con la escasez. Cultura y adaptabilidad pesquera en el lago de Chapala Perfiles Latinoamericanos, 26(51) Flacso México | pp. 89-121 | DoI: 10.18504/pl2651-004-2018 
una doble ganancia ya que afirman que posterior a 2004 tuvieron algunos años de "buena pesca". Así podemos observar una estrategia de adaptación reactiva a un momento de bonanza.

\section{Mapa 2. Parcelación de las orillas descubiertas del lago de Chapala}

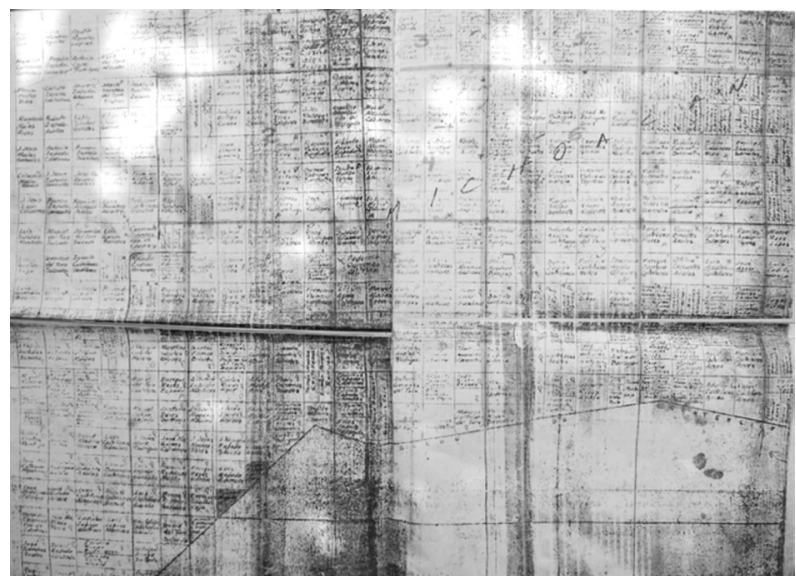

Fuente: Mapa elaborado por vecinos de La Palma con base en el del reparto de la sequía de 1952.

La ausencia de un patrón es especialmente apreciada por los entrevistados, pues les permite una mayor libertad de oficio. Los pescadores aprovechan esta autonomía en varias instancias estratégicas y de interés para nuestro tema, como en la decisión de utilizar o no motores en sus lanchas. Remar disminuye o incluso elimina los costos de producción.

La libertad de oficio también es visible en otras estrategias adaptativas. Según el directivo de una cooperativa local de pescadores (Zepeda, entrevista, 7 de noviembre de 2012), la búsqueda de especies infrecuentes en las orillas del lago induce a los pescadores a alejarse hacia zonas más profundas. Asimismo, en épocas prolongadas de estiaje, en las que sus zonas de captura habitual se secan, los pescadores simplemente deben pescar en otra parte donde sí hay agua. De esta manera aprovechan los permisos que los autorizan a pescar en todo el lago. Los obstáculos se reducen a conseguir la aprobación de otras comunidades pesqueras del lado de Jalisco, las cuales tradicionalmente tienen sus espacios bien designados.

En lo que se refiere a la contaminación, los pescadores optan por lavar las redes utilizando detergentes y cloro para quitar la lama acumulada y evitar que los peces se acerquen a ellas. Esto contribuye a la ya conocida contaminación del lago. En el caso del pescado, una vez fileteado también pasa por un proceso de 
lavado, argumentando que de no ser así se echa a perder y que ese paso disminuye o elimina el mal olor o sabor. Y respecto a las descargas residuales no se identificó ninguna estrategia adaptativa que responda específicamente a tal problemática.

\section{La permanencia de la pesca}

Como se observa, las adversidades descritas no han logrado desanimar al sector. En La Palma la pesca persiste como actividad económica y como referente en la cultura local.

En La Palma, el oficio de pescador se arraiga en la tradición familiar y en la dinámica sociocultural y política comunitaria. La actividad no se limita a la transmisión generacional, sino que se extiende a imaginarios presentes en varias facetas del mismo pueblo. En conjunto, estos factores se consideran como un esbozo de la importancia histórica y el futuro de la pesca en la ciénega de Chapala.

La importancia de la pesca en La Palma se remonta en parte al hecho de que antes de 1923 los vecinos de esta comunidad no tenían tierras. Las solicitudes existían desde tiempo atrás, sin embargo, no se las habían concedido debido a que la mayoría de los pobladores de la localidad se dedicaban a actividades diferentes a la agricultura, como la pesca (Ortiz, 2000). Esto también se explica porque en la repartición de tierras durante la reforma agraria en los años veinte y treinta — aún cuando La Palma servía de puerto importante- respondieron peones de las exhaciendas, pero no pescadores como tales. Un suceso similar se repitió en otra repartición de parcelas desecadas durante una sequía en los años cuarenta y cincuenta, a la que respondieron los entonces desocupados exfabricantes de canoas y marineros (Montes, entrevista, 27 de enero de 2013).

Ante la oportunidad de acumular medios de producción terrestre, los pescadores preferían migrar. Era más fácil y preferible para muchos de ellos enfrentar el estrés lacustre desplazándose antes que volverse agricultores. Estos movimientos podían ser regionales, como en el caso de Petatán, o internacionales.

Actualmente - y esto coincide con otros estudios sobre la cultura pesquera artesanal (McGoodwin, 2002) —, este sector en La Palma muestra gran dependencia respecto de la tradición familiar y el adiestramiento para subsistir con bajos ingresos económicos. El cronista del pueblo, Gabriel Montes, apoya esto al afirmar el oficio familiar como un referente básico, aunque no necesariamente exclusivo de los pescadores:

Primero (por) la tradición, porque aquí son familias de tradición, de pescador, como lo son los agricultores y como lo son por ejemplo los albañiles. Si usted pregunta y dice, por ejemplo, Gaitán, todo mundo sabe que los Gaitán son albañiles. 
Si usted dice Moreno, relacionan el apellido con la agricultura. Pero si usted dice, Rodríguez, ninguno tiene tierra. Todos son pescadores. Primero eso, y en segundo lugar, que por tradición lo han hecho toda la vida (27 de enero de 2013).

Así, la fidelidad a la tradición familiar también mina la acumulación de los medios necesarios para ampliar estrategias de adaptación. De esta manera las oportunidades históricas para obtener tierras sembrables y sustituir o complementar la pesca con la agricultura no fueron aprovechadas intencionalmente.

El libre acceso también es una característica básica de la actividad pesquera y fomenta la permanencia o la resistencia a cambiar de oficio. En México, ${ }^{6}$ el hecho legal de que cualquier persona pueda pescar para autosubsistencia permite a las familias tener alimento nutritivo sin incurrir en grandes gastos. Adicionado a este beneficio se da la posibilidad de vender los excedentes.

Por otra parte, hay jóvenes que afirman que pescan porque les gusta el oficio, y pescadores viejos que lo conservan porque no saben hacer otra cosa. Así, aunque las condiciones mermadas del lago motivan el cambio de oficio, existen razones para continuar en él.

La historia competitiva de la pesca local frente a otras actividades productivas también se apoya en inteligencia de observación e interpretación. Los déficits en volumen de agua, que concentran contaminantes y disminuyen la captura de peces (gráfica 4) (Hansen $\&$ Van Afferden, 2001), tienden a estar relacionados con condiciones similares en la agricultura. Dado que una fuente importante de reabastecimiento del lago es pluvial, el descenso de nivel del lago coincide con temporadas de sequías y de una mayor competencia por el agua en tierras sembradas. En contraste, grandes aumentos pluviales reabastecen el nivel del lago, pero causan inundaciones y pérdidas en el campo. Dicho de otra forma, los pescadores de linaje consideran que la seguridad laboral o de ingresos no es mucho mayor en el campo. En épocas de bonanza el ingreso puede ser mayor que en la agricultura y en épocas de secas pescar asegura el alimento. Así, un cambio de oficio no necesariamente significaría mayores ingresos o un mejor nivel de vida. En este mismo sentido, uno de los jefes de cooperativa de La Palma explica por qué continúan pescando: "La pesca está mala, está raquítica, pero sí se mantiene uno bien y todo, porque ya estamos impuestos a que a veces nos va bien, a veces nos va mal, pero sí sale para comer" (Salvador Comparan Zamarripa, Jefe de Cooperativa de La Palma, entrevista, 24 de octubre de 2013).

Además de la competencia histórica con la ganadería y la agricultura, los pescadores de La Palma han tenido que responder al aumento de contaminantes, a la desecación repetida, al sobreaprovechamiento del agua extraída y a la

6 Gobierno de México, Ley General de Pesca y Acuacultura Sustentables, 2007, Art. 72. 
introducción de especies exóticas. Es aquí donde su aprendizaje sociocultural, basado en su conocimiento de la pesca y el lago, ayuda a la adaptación y evolución de la tecnología pesquera y de las instituciones sociales para poder continuar pescando.

\section{Discusión}

La pesca, que durante la época prehispánica fue la actividad productiva central en la región del lago de Chapala, para el siglo XxI se coloca como una actividad apenas viable para la subsistencia familiar. Desde mucho antes, en la época del Porfiriato, ya se le consideraba como una actividad "complementaria" (Vargas, 1989: p. 88), y después, en la etapa posrevolucionaria, se vio permanentemente relegada, al grado que los historiadores consideraban a la región de predominio "campesino" (Vargas, 1989: p. 81). La importancia histórica disminuida y aislada de la pesca en los planes de desarrollo nacional en lo tocante a aguas interiores la ha convertido en una actividad deficientemente planeada e insuficientemente controlada.

Pero si bien factores sociopolíticos, económicos e industriales han contribuido a la decadencia pesquera en la ciénega de Chapala, es importante resaltar que el mismo lago, en su calidad de cuerpo natural, también ha experimentado transformaciones, como fluctuación de volumen y desplazamiento de su orilla. De hecho algunos estudiosos constatan que "ha sido tan grande la transformación sufrida que podría resultar irreconocible la región si se confrontara el paisaje prehispánico con el actual" (Covarrubias \& Ojeda, 2009: p. 43).

En conjunto, se trata de transformaciones antropogénicas y naturales que repetidamente obligan a comunidades pesqueras a refugiarse en estrategias de adaptación. La eficacia de estas acciones, sean propiamente reactivas o proactivas, ha evitado que la pesca se coloque como una actividad residual, y hoy día aún se considera importante para las comunidades ribereñas del lago de Chapala.

Resulta interesante que estas acciones adaptativas se enfocan en preservar el estatus de la actividad pesquera mediante ayudas al sector que le permitan convivir con las modificaciones ambientales antes que revertirlas (Coulthard, 2012). Así se evita poner en riesgo las identidades, en este caso milenarias, basadas en el aprovechamiento del lago y en la agencia necesaria para enfrentar vulnerabilidades económicas y ambientales (Macken, 2009).

Las grandes transformaciones que resultaron permanentes corresponden a modelos gubernamentales productivistas de desarrollo, los cuales reorganizaron el paisaje lacustre al dictar las actividades económicas de la región. Para la administración porfirista, la visión del ejecutivo federal fue preponderante en las rea- 
lidades de la ciénega de Chapala, actitud perpetuada luego por el "paternalismo científico" de los posrevolucionarios (Boyer, 2007). Sus objetivos de desarrollo regional y nacional consistieron en fortalecer la principal unidad de producción vigente, misma que durante la Colonia y hasta el siglo xx fue la hacienda y posteriormente la cooperativa laboral en la que destacó el ejido agrario.

En estos casos, las respuestas adaptativas por parte de los pescadores y respecto de la pesca corresponden a un enfoque proactivo, ya que los cambios no derivaron de una iniciativa o necesidad de la comunidad pesquera. Es decir, los factores exógenos que afectaron sus realidades inmediatas fueron de tal intensidad y permanencia que se previeron respuestas planeadas y proactivas.

En lo tocante a los retos asociados con volúmenes y precios bajos de productos pesqueros, la adaptación es también proactiva y ha consistido en que los pescadores han transformado sus artes de pesca para permitir una mayor captura, pensando que así obtendrán mayores ingresos. Sin embargo, esta estrategia se percibe como una mala adaptación (Grothmann \& Patt, 2005), ya que, si no de manera intencional, incrementa el daño a los recursos pesqueros y ambientales a mediano y largo plazos.

Por otra parte, los cambios ocasionados por fenómenos naturales generan respuestas adaptativas de ambos tipos: fenómenos repentinos como inundaciones se enfrentan reactivamente, mientras que aquellos de progresión gradual durante extensos periodos de tiempo, como sequías, se atienden con medidas proactivas. La estrategia en estos casos tiende a soluciones prolongadas como los mencionados repartos parcelarios dentro de La Comarca del lago.

Como lo exponen Boyd \& Richerson (2006), el aprendizaje social ha permitido, entre estos pescadores, utilizar las reservas de información adaptativa acumulada por generaciones, que se expresa en su conocimiento y prácticas tradicionales que han proporcionado las bases para implementar estrategias adaptativas que responden a los diferentes obstáculos que enfrentan al tratar de ejercer su actividad en el lago de Chapala. Un ejemplo de esto es la readaptación de las artes de pesca, cuya elaboración se ha transmitido de padres a hijos $\mathrm{y}$ ante las actuales circunstancias de escasez las nuevas generaciones hacen uso de este conocimiento para modificar las redes utilizadas.

Así, a través de diferentes eventos históricos y problemas contemporáneos se observa cómo la capacidad adaptativa de los pueblos lacustres se ha ido formando como respuesta a los cambios ambientales físicos y a los político-económicos (Devenán, 1983) que ha experimentado la región.

La capacidad adaptativa puede ser determinante para la sobrevivencia de una cultura (O’Brien \& Holland, 1992), no solo para la pesca en la cienéga de Chapala, sino que es un fenómeno reconocido y estudiado en los lagos someros tropicales en otras partes del mundo como los lagos Chad y Chilwa en África 
(Sarch \& Allison, 2000), por ser ecosistemas de gran variabilidad natural. En estas circunstancias, los pescadores deben usar el conocimiento adquirido tras generaciones para pescar o sembrar. Con estos ejemplos podemos ver cómo la capacidad adaptativa aporta no solo a una actividad en particular sino que es esencial para diferentes procesos de cambio socioambiental, pudiendo ser naturales como un huracán, o inducidos como la introducción de especies exóticas.

Como se ha visto, la disyuntiva entre pescar, sembrar o cambiar de oficio, aunque sea de manera temporal, se atiende desde una variedad de posturas y con herramientas específicas en cada caso. Según Béné \& Friend (2011), los pescadores con el portafolio más amplio de actividades son los que tienen mayores posibilidades de mejorar su nivel de vida. Pero si bien las idiosincrasias de la cultura pesquera limitan y hasta obstaculizan el aprovechamiento de varias opciones, los pescadores aún muestran considerable capacidad e interés en legitimar su oficio ante escenarios de escasez. En nuestro estudio específico, los pescadores de La Palma implementan primero diferentes tipos de respuestas adaptativas que los puedan mantener dentro del circuito de actividad pesquera, antes de convertirse de manera permanente a otro oficio.

\section{Reflexiones finales}

La presencia y la cualidad cambiante del lago de Chapala ha sido un factor determinante de las actividades productivas en sus comunidades ribereńas. Pero, como se ha revisado, asumir la pesca como una de las más favorecidas puede ser erróneo. De hecho, para La Palma, Michoacán, el análisis histórico revela que la pesca ha sido constantemente amenazada por otras actividades.

En cuanto a las respuestas adaptativas se ha observado que se basan en dos aspectos: el costo de oportunidad y las tradiciones familiares. Se continúa pescando porque es una actividad de fácil acceso con la que se obtienen alimentos, además de que es una práctica que en La Palma ha sucedido por generaciones.

En otras palabras, es posible concebir la adaptación como un elemento que aporta o incentiva estrategias de organización social. Se seleccionan formas de actuar a través de las cuales se ha permitido la sobrevivencia de la cultura pesquera y una parte importante de la esencia de la comunidad de La Palma.

Los pescadores han demostrado ser un grupo dinámico que se ha adaptado a los cambios en el medio físico. Manteniendo su integridad como pescadores, han implementado estrategias favorables para dar continuidad a la actividad pesquera, como, por ejemplo, seguir el agua. Pero también han optado por malas estrategias, como el uso de artes de pesca prohibidos, lo que resulta en una limitante para la continuidad de su actividad. 
La pesca ha logrado sobrevivir gracias a la capacidad de adaptación de los pescadores, el conocimiento transgeneracional, su fidelidad a la tradición y a que se trata de una actividad de libre acceso que deriva en ingresos económicos. Sin embargo, las limitantes ambientales del lago causadas por actividades antropogénicas y fenómenos naturales, aunadas a las estrategias nocivas de adaptación, no parecen motivar un futuro promisorio para la pesca de captura continental en este cuerpo de agua.

\section{Referencias}

Aparicio, J. (2001). Hydrology of The Watershed. En Hansen, A. M. \& Afferden, M. van (Eds.). The Lerma-Chapala Watershed. Evaluation and Management (pp. 3-30). Nueva York: Kluwer Academic Press.

Arredondo-Vargas, E., Osuna-Paredes, C., Meléndez-Galicia, C., Jesús-Avendaño, C. \& Hernández-Montaño, D. (2013). Lago de Chapala, Michoacán y Jalisco. En Gaspar-Dillanes M. T. \& Hernández-Montaño, D. (Comps.). Pesquerías continentales de México (pp. 3-30). México: Instituto Nacional de la Pesca.

Benard, R. (2006). Research Methods in Anthropology, Qualitative and Quantitative Approaches. Lanham: Altamira Press.

Béné, C. \& Richard, F. (2011). Poverty in Small-scale Fisheries. Old Issue, New Analysis. Progress in Development Studies, 11(2), 119-144.

Boyd, R. \& Richerson, P. C. (2006). Culture, Adaptation, and Innateness. En Carruthers, P., Laurence, S. \& Stich, S. P. (Eds.). The Innate Mind. Volume 2: Culture and Cognition. Nueva York: Oxford University Press.

Boyer, C. (2007). Revolución y paternalismo ecológico: Miguel Ángel de Quevedo y la política forestal en México, 1926-1940. Historia Mexicana, LVII(I), 91-138.

Burton, T. (2008). Lake Chapala Through the Ages; An Anthology of Travellers' Tales. Vancouver Island: Sombrero Books.

Carranza Frazer, J. (1953). Historia de la piscicultura en México. Memoria del Congreso Científico Mexicano, VIII Ciencias Biológicas (pp. 159-174). México: UnAM.

Castellanos Moreno, J. J. (2011). Museo Vivo. Proyecto de difusión cultural. Tesis de Licenciatura en Estudios Multiculturales. Universidad de La Ciénega del Estado de Michoacán de Ocampo, Sahuayo, Michoacán, México. 
Comisión Estatal del Agua-Jalisco. (2013). Niveles del Lago de Chapala. Recuperado el 18 de septiembre de 2017, de http://www.ceajalisco.gob.mx/contenido/chapala/

Contreras Alvarado, M. (2012). Los inicios de la piscicultura en México: actores y redes (18831892). Tesis de maestría. Centro de Investigaciones Económicas, Administrativas y Sociales-Instituto Politécnico Nacional. México.

Coops, H., Beklioglu, M. \& Crisman, T. L. (2003). The Role of Water-level Fluctuations in Shallow Lake Ecosystems-workshop Conclusions. Hydrobiologia, 506(1-3), 23-27.

Cotler, H. \& Gutiérrez, S. (2005). Inventario y evaluación de presas de la cuenca Lerma-Chapala. México: INE.

Coulthard, S. (2012). Can We be Both Resilient and Well, and What Choices do People Have? Incorporating Agency into the Resilience Debate from a Fisheries Perspective. Ecology and Society, 17(1), 4 .

Covarrubias Villa, F. (2007). Las transformaciones históricas de la producción agricola en la ciénega de Chapala. Ponencia dada en la Asociación Mexicana de Ciencias para el Desarrollo Regional, A. C., Tlaxcala. Recuperado el 18 de septiembre de 2017, de http://www.eumed .net/jirr/1/AMECIDER2007/indice2.htm

Covarrubias Villa, F. \& Ojeda Sampson, A. (2009). Poblamiento y agricultura en la Ciénaga de Chapala. Zamora, México: Instituto de Investigaciones Sociales y Humanas-Instituto Politécnico Nacional.

Diario Oficial de la Federación (DOF) (2006). Acuerdo mediante el cual se aprueba la actualización de la Carta Nacional Pesquera, DOF, 25 de agosto.

Fernández Guzmán, E. (2011). Migración internacional en un pueblo michoacano. Retorno e inversión migrante (1982-2008): El caso Huandacareo. México: Pearson.

Filonov, A. E., Tereshchenko, I. E., \& Monzón, C. O. (1998). Oscillations of the Hydrometeorological Characteristics in the Region of Lake Chapala for Intervals of Days to Decades. Geofisica Internacional, 37(4), 293-307.

Gaspar Dillanes, M. T. \& Hernández Montaño, D. (2013). Pesquerías continentales de México. México, Inapesca.

Gatti, M. L. (1986). Los pescadores de México: La vida en un lance. México: CIESAS/MNCP.

Gil Méndez, J. (2009). Actividad agrícola y migración internacional en localidades rurales del Valle de Ixtlán, Michoacán. Textual. Análisis del Medio Rural Latinoamericano, (54), 31-54.

118 - C. Pedroza Gutiérrez, J. Chavolla | Conviviendo con la escasez. Cultura y adaptabilidad pesquera en el lago de Chapala Perfiles Latinoamericanos, 26(51) FLacso México | pp. 89-121 | DoI: 10.18504/pl2651-004-2018 
Grothmann, T. \& Patt, A. (2005). Adaptive Capacity and Human Cognition: The Process of Individual Adaptation to Climate Change. Global Environmental Change, (15), 199-213.

Hansen, A. \& Afferden, M. van (2001). The Lerma-Chapala Watershed Evolution and Management. Nueva York: Kluwer Academic/Plenum Publishers.

Klein, R. J. T. (1998). Towards Better Understanding, Assessment and Funding of Climate Adaptation. Change, (44), 15-19.

Lameiras, B. de (1985). Cultura criolla y migración en la Ciénega de Chapala. Relaciones, IV(24), 91-110.

López Hernández, M., Ramos-Espinosa, M. G. \& Carranza Fraser, J. (2007). Análisis multimétrico para evaluar contaminación en el río Lerma y el Lago de Chapala. Hidrológica, 17(1), 17-30.

Macken Walsh, A. (2009). Barriers to Change: a Sociological Study of Rural Development in Ireland. Dublin: Teagasc Rural Economy Research Centre.

McGoodwin, J. R. (2002). Comprender las culturas de las comunidades pesqueras. Clave para la ordenación pesquera y la seguridad alimentaria. FAO, documento técnico de pesca 401.

Moncayo-Estrada, R., Lyons, J., Escalera-Gallardo, C. \& Lind, O. (2012). Long-term Change in The Biotic Integrity of a Shallow Tropical Lake: A Decadal Analysis of the Lake Chapala Fish Community. Lake and Reservoir Management, 28(1), 92-104.

Montes Ayala, F. G. (1991). Ensayo histórico y estadístico de Venustiano Carranza y su municipalidad. Sahuayo, Mich. México: Presidencia Municipal de Venustiano Carranza.

Montes Vázquez, F. J. \& Montes Ayala, F. G. (2008). La Palma de Jesús. Una historia y un pasado. México: Sociedad Michoacana de Historia, Arqueología y Geografía.

Mestre Rodríguez, J. E. (1997). Case Study VIII-Lerma-Chapala Basin, Mexico. En Helmer, R. \& Hespanhol, I. (Eds.). Water Pollution Control-A Guide to the Use of Water Quality Management Principles (pp. 377-391). Londres: World Health Organization/United Nations Environment Programme.

WHO-ENEP. Recuperado el 7 de diciembre de 2012, de http://www.who.int/water_sanitation_ health/resourcesquality/wpccasestudy8.pdf

Mummert, G. (1994). Tierra que pica. Transformación social de un valle agricola michoacano en la época post-reforma agraria. Zamora: El Colegio de Michoacán. 
O’Brien, M. J. \& Holland, T. D. (1992). The Role of Adaptation in Archeological Explanation. American Antiquit, 57(1), 36-59.

Organización para la Cooperación y el Desarrollo Económicos (OECD) (2007). Structural Change in Fisheries: Dealing with the Human Dimension. París: Organisation for Economic Cooperation and Development.

Okolodkov, Y., Bastida-Zavala, B. R., Ibáńez, A. L., Chapman, J. W., Suárez-Morales, E., Pedroche, F. \& Gutiérrez-Mendieta, F. J. (2007). Especies acuáticas no indígenas en México. Ciencia y Mar, 11(32), 29-67.

Ortiz Segura, C. (2001). Todo tiempo pasado fue mejor, o la pesca en el lago de Chapala antes de la desecación de su ciénega. Gazeta de Antropología 17: artículo 26. Recuperado el 18 de septiembre de 2017, de http://hdl.handle.net/10481/7486

Ortiz Segura, C. (2000). Pesca y deterioro ecológico en el Lago de Chapala: El caso de La Palma, Michoacán. Tesis de Maestría en Antropología Social. Centro de Estudios AntropológicosEl Colegio de Michoacán. México.

Paré, L. (1989). Los pescadores de Chapala y la defensa de su lago. Tlaquepaque, Jal., México: Instituto Tecnológico y de Estudios Superiores de Occidente.

Risbey, J., Kandlikar, M. \& Dowlatabadi, H. (1999). Scale, Context and Decision Making in Agricultural Adaptation to Climate Variability and Change. Mitigation and Adaptation Strategies for Global Change 4(2), 137-165.

Rojas Carrillo, P. M. \& Sasso Yada, L. (2005). El pescado blanco. Revista Digital Universitaria, $8(6), 2-18$

Sarch, M. T. \& Allison, E. H. (2001). Fluctuating Fisheries in Africa's Inland Waters: Well Adapted Livelihoods, Maladapted Management. En Johnston, R. S. (Ed.). Microbehavior and Macroresults: Proceedings of the Tenth Biennial Conference of the International Institute of Fisheries Economics and Trade, July 10-14, 2000, Corvallis, Oregon, USA. International Institute of Fisheries Economics and Trade (IIFET), Corvallis, OR, 2001. CD ROM. Recuperado el 18 de septiembre de 2017, de https:/ir.library.oregonstate.edu/xmlui/bitstream/ handle/1957/30935/101.pdf?sequence=1

Sarch, M. T. \& Birkett, C. (2000). Fishing and Farming at Lake Chad: Responses to Lake-Level Fluctuations. The Geographical Journal, 166(2), 156-172.

Sistema Intermunicipal de los Servicios de Agua Potable y Alcantarillado (SIAPA) (2013). Trabajos de mantenimiento acueducto Chapala-Guadalajara. Recuperado el 29 de marzo de 2013, de http://www.siapa.gob.mx/prensa/siapa-informa-12 
Smith, B., Burton, I., Klein, R. \& Wandel, J. (2000). An Anatomy of Adaptation to Climate Change and Variability. Climatic Change, 45(1), 223-251.

Smith, B. \& Wandel, J. (2006). Adaptation, Adaptive Capacity and Vulnerability. Global Environmental Change, 16(3), 282-292.

Stahle, D. W., Diaz, J. V., Burnette, D. J., Paredes, J. C., Heim Jr., R. R., Fye, F. K., Acuña Soto, R., Therrell, M. D., Cleaveland, M. K., \& Stahle, D. K. (2011). Major Mesoamerican Droughts of the Past Millennium. Geophysical Research Letters, (38), 1-4.

Tereshchenko, I., Afilonov, A., Gallegos, A., Monzón, C. \& Rodríguez, R. (2002, 30 de julio). El Niño 1997-98 and the Hydrometeorological Variability of Chapala, a Shallow Tropical Lake in Mexico. Journal of Hydrology, 264(1-4), 133-146.

Vargas González, P. E. (1989). Venustiano Carranza: el conflicto político en la constitución del municipio. En Zendejas, S., (Coord.) Estudios michoacanos III (pp. 3-30). Zamora: El Colegio de Michoacán.

Vega, M. Y. de la. (2003, octubre-diciembre). Situación de los peces dulceacuícolas en México. Ciencias, (72), 20-30.

Denevan, W. M. (1983). Adaptation, Variation and Cultural Geography. Professional Geographer 35(4), 399-406.

Villanueva Díaz, J., Cerano Paredes, J., Benavides, J. D., Stahle, D. W., Estrada Ávalos, J., Constante García, V. \& Tostado Placencia, M. (2012). Reconstrucción de los niveles del Lago de Chapala con series dendrocronológicas de Taxodium mucronatum. Revista Mexicana de Ciencias Forestales, 3(14), 55-68.

Welcomme, R. (2011). Review of the State of the World Fishery Resources: Inland Fisheries. FAO Fisheries and Aquaculture. Circular 942, Rev. 2. Roma.

Wicki, G. \& Gromenida, N. (1998). Estudio de desarrollo y producción de tilapia (Oreochromis niloticus). Revista AquaTIC, 2.

Wolfe, M. (2013). The Historical Dynamics of Mexico's Groundwater Crisis in La Laguna: Knowledge, Resources and Profit, 1930s-1960s. Mexican Studies, 29(1), 3-35.

Recibido el 1 de octubre de 2015. Aceptado el 6 de octubre de 2016. 